\title{
NOTES
}

\section{Anionic Polymerization of Fluoroalkyl 2-Trifluoromethylacrylate}

\author{
Tadashi Narita, ${ }^{*}$ Tokio Hagiwara, Hiroshi Hamana, \\ and Shuichiro MAESAKA \\ Department of Environmental Engineering, Saitama Institute of Technology, \\ 1690 Okabe-machi, Osato-gun, Saitama 369-02, Japan
}

(Received January 23, 1988)

\begin{abstract}
KEY WORDS Anionic Polymerization / 2,2,2-Trifluoroethyl 2-Trifluoromethylacrylate / 2,2,2-Trifluoro-1-trifluoromethylethyl 2-Trifluoromethylacrylate /
\end{abstract}

Fluorine-containing acrylate polymers have recently come to attract much attention in the fields of X-ray and electron beam lithography. The reactivity of fluorine-containing acrylates toward carbanions may be increased since fluoroalkyl substituents possess a high electron-withdrawing effect which reduces the electron density of vinyl groups. The high $\mathrm{e}$ values of fluoroalkyl acrylates, methacrylates and methyl 2-trifluoromethylacrylate have been reported. ${ }^{1,2}$ It has recently been pointed out that fluoroalkyl acrylates and methacrylates are polymerized anionically with initiators of low basicity. ${ }^{3-7}$ The anionic polymerization of alkyl 2-trifluoromethylacrylates have been reported by two research groups. ${ }^{8-10}$ Since the e value of methyl 2trifluoromethylacrylate is as high as 2.9 , the anionic polymerization of alkyl 2-trifluoromethylacrylate is expected to take place with initiators of low basicity; that is, the polymers of ethyl 2-trifluoromethylacrylate are obtained with lithium tert-butoxide, potassium tertbutoxide, triethylaluminum, and diethyl(ethyl cyanoacetato)aluminum as initiator. Ito et al. have also reported that methyl 2-trifluoro- methylacrylate is polymerized with alkali metal salts complexed with 18 -crown-6. ${ }^{11}$

The present paper deals with the anionic polymerization of the acrylates possessing two fluoroalkyl groups such as 2,2,2-trifluoroethyl 2-trifluoromethylacrylate (TFTFA) and 2,2,2-trifluoro-1-trifluoromethylethyl 2-trifluoromethylacrylate (HxFTFA) with several initiators.

\section{EXPERIMENTAL}

Experiments were carried out under a purified nitrogen atmosphere to preclude oxygen and atmospheric moisture.

\section{Reagents}

2,2,2-Trifluoroethyl 2-trifluoromethylacrylate (TFTFA) and 2,2,2-trifluoro-1-trifluoromethylethyl 2-trifluoromethylacrylate ( $\mathrm{HxF}$ TFA) (from Central Glass Co.) were refluxed over calcium hydride and then distilled; TFTFA, bp $52^{\circ} \mathrm{C} / 53 \mathrm{mmHg}$; HxFTFA, bp $41^{\circ} \mathrm{C} / 50 \mathrm{mmHg}$. Commercial $n$-butyllithium (hexane solution) and $n$-butylmagnesium chloride (ether solution) were used after

\footnotetext{
* To whom all correspondence should be addressed.
} 
determination of the concentrations of the active species by alkalimetry. Lithium tertbutoxide and potassium tert-butoxide were synthesized from corresponding metals with tert-butanol, respectively. $\mathrm{Zn}\left(\mathrm{C}_{2} \mathrm{H}_{5}\right)_{2}$ and $\mathrm{Al}$ $\left(\mathrm{C}_{2} \mathrm{H}_{5}\right)_{3}$ were distilled under reduced pressure. $\mathrm{LiZnC}_{4} \mathrm{H}_{9}\left(\mathrm{C}_{2} \mathrm{H}_{5}\right)_{2}$ and $\mathrm{LiAlC}_{4} \mathrm{H}_{9}\left(\mathrm{C}_{2} \mathrm{H}_{5}\right)_{3}$ were synthesized from $n$-butyllithium and $\mathrm{Zn}$ $\left(\mathrm{C}_{2} \mathrm{H}_{5}\right)_{2}$ or $\mathrm{Al}\left(\mathrm{C}_{2} \mathrm{H}_{5}\right)_{3}$, respectively. Ethyl(acetylacetonato)zinc $\left(\mathrm{C}_{2} \mathrm{H}_{5} \mathrm{Znacac}\right)$, ethyl(ethyl cyanoacetato)zinc $\left(\mathrm{C}_{2} \mathrm{H}_{5} \mathrm{ZnECA}\right)$ and diethyl(ethyl cyanoacetato)aluminum $\left(\left(\mathrm{C}_{2} \mathrm{H}_{5}\right)_{2} \mathrm{AlECA}\right)$ were synthesized according to the literature. ${ }^{12}$ Toluene, tetrahydrofuran (THF) and 1,2-dimethoxyethane (DME) were purified by usual methods.

\section{Procedures}

Polymerization was carried out in a glass ampule charged with monomer $(5 \mathrm{mmol})$, ini- tiator $(0.1 \mathrm{mmol})$ and solvent $(5 \mathrm{ml})$ under nitrogen. The ampule was sealed and kept at $60^{\circ} \mathrm{C}$. After an appropriate time interval, the polymer was isolated by precipitation with methanol and dried to constant weight. When a precipitate was not obtained, methanol was removed under reduced pressure and the residue was extracted with benzene. The solution was washed with diluted hydrochloric acid in order to get rid of initiator residue and the polymer was obtained by removing benzene by lyophilization.

\section{Measurements}

${ }^{1} \mathrm{H}$ NMR spectra were registered at $60 \mathrm{MHz}$ on a HITACHI model R-600 FT-NMR spectrometer. Infrared (IR) spectra ( $\mathrm{KBr}$ disk method) were measured on a SHIMADZU IR-400 spectrophotometer. Gel permeation chromatography (GPC) was measured with

Table I. Anionic polymerization of fluoroalkyl 2-trifluoromethylacrylates

\begin{tabular}{|c|c|c|c|c|}
\hline Initiator & Solvent & Time/day & $\begin{array}{c}\text { Poly(TFTFA) } \\
\text { yield } / \%\end{array}$ & $\begin{array}{c}\text { Poly(HxFTFA }) \\
\text { yield } / \%\end{array}$ \\
\hline \multirow[t]{2}{*}{$n-\mathrm{C}_{4} \mathrm{H}_{9} \mathrm{Li}$} & THF & 7 & 54.3 & 25.2 \\
\hline & DME & 7 & 59.0 & 11.1 \\
\hline \multirow[t]{2}{*}{$n-\mathrm{C}_{4} \mathrm{H}_{9} \mathrm{MgCl}$} & THF & 7 & 7.6 & 41.1 \\
\hline & DME & 7 & 11.5 & 14.2 \\
\hline \multirow{3}{*}{$\mathrm{LiZnC}_{4} \mathrm{H}_{9}\left(\mathrm{C}_{2} \mathrm{H}_{5}\right)_{2}$} & THF & 10 & 68.5 & 12.5 \\
\hline & DME & 7 & 69.0 & 16.1 \\
\hline & Toluene & 10 & 0 & 0 \\
\hline \multirow{2}{*}{$\mathrm{LiAlC}_{4} \mathrm{H}_{9}\left(\mathrm{C}_{2} \mathrm{H}_{5}\right)_{3}$} & THF & 10 & 0 & 7.2 \\
\hline & Toluene & 10 & 0 & 0 \\
\hline \multirow[t]{3}{*}{$t-\mathrm{C}_{4} \mathrm{H}_{9} \mathrm{OLi}$} & THF & 10 & 37.1 & 10.1 \\
\hline & DME & 7 & 11.5 & 11.1 \\
\hline & Toluene & 7 & 0 & 0 \\
\hline \multirow[t]{2}{*}{$t-\mathrm{C}_{4} \mathrm{H}_{9} \mathrm{OK}$} & THF & 7 & 0 & 0.6 \\
\hline & DME & 7 & 0 & 16.3 \\
\hline \multirow[t]{2}{*}{$\mathrm{Zn}\left(\mathrm{C}_{2} \mathrm{H}_{5}\right)_{2}$} & THF & 10 & 0 & 0 \\
\hline & Toluene & 10 & 0 & 0 \\
\hline \multirow[t]{2}{*}{$\mathrm{C}_{2} \mathrm{H}_{5} \mathrm{Znacac}$} & THF & 7 & 34.2 & 5.0 \\
\hline & Toluene & 7 & 0 & 2.7 \\
\hline \multirow[t]{2}{*}{$\mathrm{C}_{2} \mathrm{H}_{5} \mathrm{ZnECA}$} & THF & 7 & 0 & 0 \\
\hline & Toluene & 7 & 0 & 0 \\
\hline \multirow[t]{2}{*}{$\mathrm{Al}\left(\mathrm{C}_{2} \mathrm{H}_{5}\right)_{3}$} & THF & 10 & 0 & 2.3 \\
\hline & Toluene & 10 & 0 & 0 \\
\hline \multirow[t]{2}{*}{$\left(\mathrm{C}_{2} \mathrm{H}_{5}\right)_{2} \mathrm{AlECA}$} & THF & 10 & 0 & 3.0 \\
\hline & Toluene & 10 & 0 & 0 \\
\hline
\end{tabular}

${ }^{a}$ Polymerization temperature, $60^{\circ} \mathrm{C}$. 
a TOYO SODA HLC-820A equipped with a TSK gel G4000HXL-G3000HXL-G2000HXL column series using THF as the eluent. Thermogravimetry (TG) and differential scanning calorimetry (DSC) were performed with a RIGAKU DENKI TG-DSC calorimeter.

\section{RESULTS AND DISCUSSION}

Since the methyl and ethyl esters of 2trifluoromethylacrylic acid are hardly polymerized with radical initiator, ${ }^{10}$ the polymerizations of 2,2,2-trifluoroethyl 2-trifluoromethylacrylate (TFTFA) and 2,2,2-trifluoro1-trifluoromethylethyl 2-trifluoromethylacrylate (HxFTFA) were examined using anionic initiators. Table I shows the results of TFTFA<smiles>[R]C(=O)C(=C)C(F)(F)F</smiles>

$$
\text { TFTFA : } \mathrm{R}_{\mathrm{f}}=\mathrm{CH}_{2} \mathrm{CF}_{3}
$$$$
\mathrm{HxFTFA}: \mathrm{R}_{\mathrm{f}}=\mathrm{CH}\left(\mathrm{CF}_{3}\right)_{2}
$$

and HxFTFA with several anionic initiators. $n$-Butyllithium and $\mathrm{LiZnC}_{4} \mathrm{H}_{9}\left(\mathrm{C}_{2} \mathrm{H}_{5}\right)_{2}$ are the most effective initiators for polymerization of TFTFA in THF and DME. HxFTFA is also polymerized with $n$-butyllithium, $n$-butylmagnesium chloride and $\mathrm{LiZnC}_{4} \mathrm{H}_{9}\left(\mathrm{C}_{2} \mathrm{H}_{5}\right)_{2}$. These results are in contrast to those reported by Ito et al. ${ }^{10}$ according to which $n$-butyllithium does not produce poly(methyl 2-trifluoromethylacrylate). Lithium tert-butoxide as initiator gives appreciable yields of poly(TFTFA) and poly(HxFTFA). Organozinc and organoaluminum compounds, by some of which it is possible to produce poly(ethyl 2-trifluoromethylacrylate), ${ }^{9}$ are inactive for polymerizations of TFTFA and HxFTFA but active for the $\mathrm{C}_{2} \mathrm{H}_{5} \mathrm{Znacac}-\mathrm{TFTFA}$ systems. THF and DME are found to be preferable solvent compared with toluene as far as polymer yields are concerned.
Table II. Solubility of poly(TFTFA) and poly(HxFTFA) ${ }^{a}$

\begin{tabular}{lcc}
\hline \multicolumn{1}{c}{ Solvent } & Poly(TFTFA) Poly(HxFTFA) \\
\hline Methanol & ++ & - \\
Ethanol & ++ & - \\
1,2-Dimethoxyethane & ++ & - \\
1,4-Dioxane & ++ & - \\
Tetrahydrofuran & ++ & - \\
Chloroform & + & - \\
Acetone & ++ & - \\
Toluene & + & - \\
Benzene & ++ & - \\
Cyclohexane & + & - \\
Hexane & + & - \\
Hexafluorobenzene & ++ & - \\
\hline
\end{tabular}

a ++ , soluble; + , partially soluble; - , insoluble.

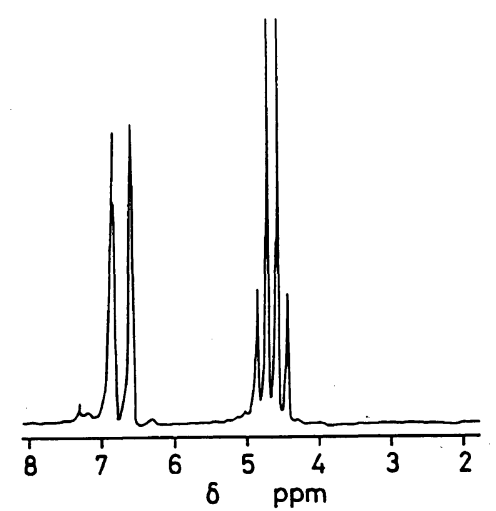

(A)

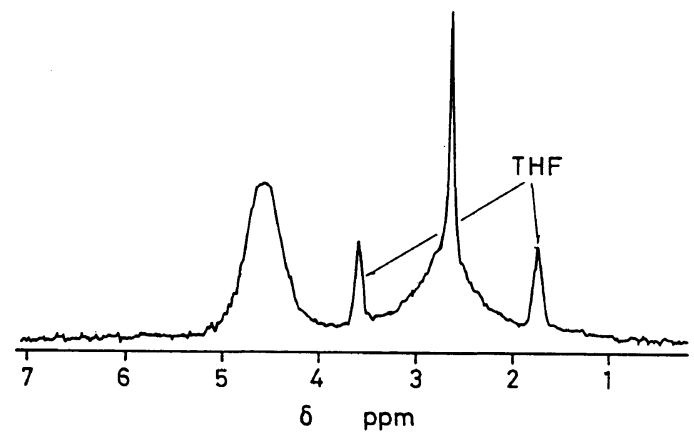

(B)

Figure 1. ${ }^{1} \mathrm{H}$ NMR of TFTFA (A) and poly(TFTFA) (B) produced with $n-\mathrm{C}_{4} \mathrm{H}_{9} \mathrm{Li}$ in THF at $60^{\circ} \mathrm{C}$ for 7 days.

It is apparent that the polymer yields are lower compared to those in the usual polymerization of alkyl acrylates and methacrylates, 


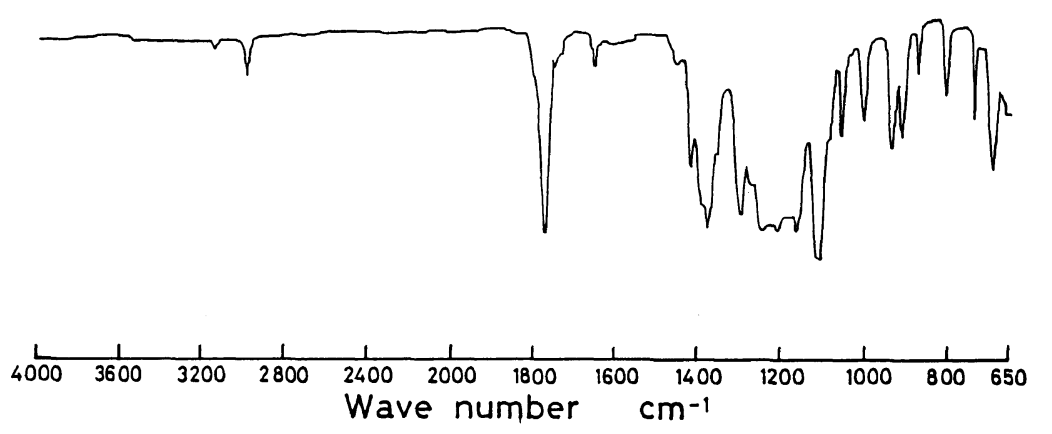

(A)

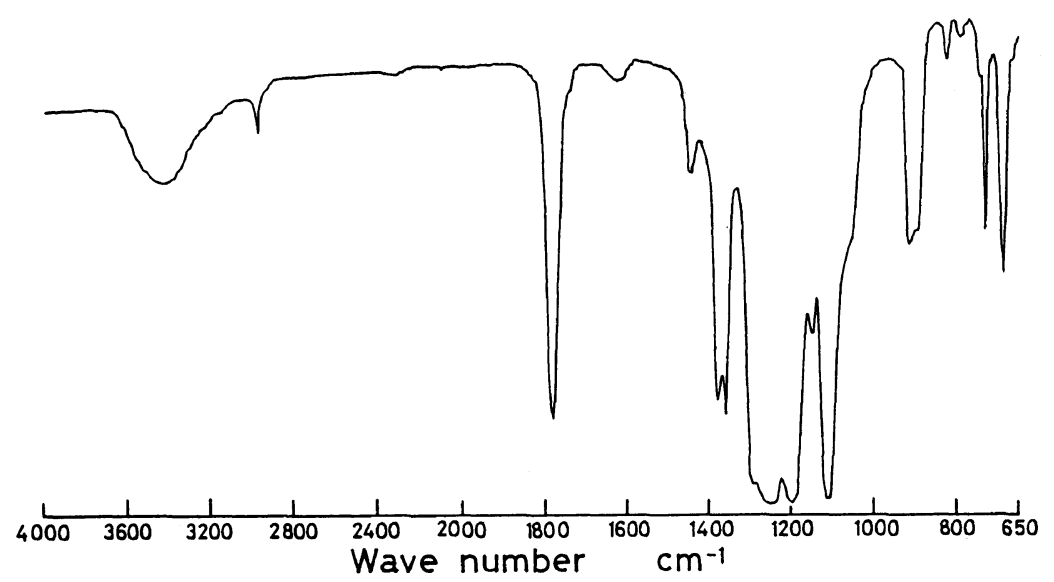

(B)

Figure 2. IR spectra of HxFTFA (A) and poly(HxFTFA) (B) produced with $n-\mathrm{C}_{4} \mathrm{H}_{9} \mathrm{MgCl}$ in THF at $60^{\circ} \mathrm{C}$ for 7 days.

probably because the electron density of the carbanions at propagating end groups may be also decreased by the electron-withdrawing effect of fluoroalkyl groups.

Produced poly(TFTFA) was soluble or partly soluble in the such solvents as alcohols, ethers, hydrocarbons and hexafluorobenzene, but no solvent was found for poly $(\mathrm{HxF}$ TFA), which behaved similarly as poly(tetrafluoroethylene), as shown in Table II. The polymerization system of HxFTFA, therefore, becomes gelatinous as the reaction proceeds.

Figure 1 shows the ${ }^{1} \mathrm{H}$ NMR spectra of TFTFA and poly(TFTFA) produced with $n$ $\mathrm{C}_{4} \mathrm{H}_{9} \mathrm{Li}$ in THF. Signals at $\delta=4.6$ and 2.65 in

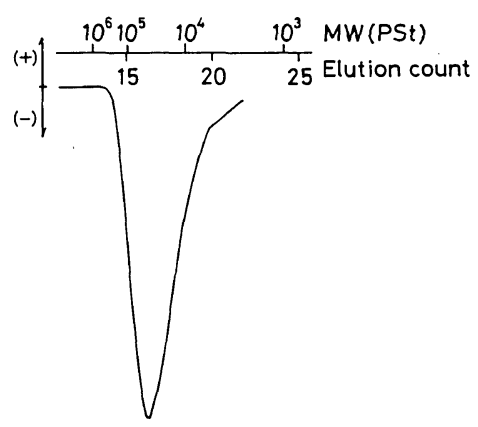

Figure 3. GPC eluogram of poly(TFTFA) obtained with $\mathrm{LiZnC}_{4} \mathrm{H}_{9}\left(\mathrm{C}_{2} \mathrm{H}_{5}\right)_{2}$ in DME at $60^{\circ} \mathrm{C}$ for 7 days.

Figure 1(B) are assigned to the methylene protons of trifluoroethyl group and the main chain, respectively, with an intensity ratio of 
$1: 1$. No peak assignable to vinylic protons is observed. Figure 2 shows the IR spectra of HxFTFA and poly(HxFTFA) produced with $n-\mathrm{C}_{4} \mathrm{H}_{9} \mathrm{MgCl}$ in THF since the polymer is insoluble in any solvent for measuring the ${ }^{1} \mathrm{H}$ NMR spectrum. The absorptions at $870 \mathrm{~cm}^{-1}$ and $1650 \mathrm{~cm}^{-1}$ assignable to vinyl group of HxFTFA disappeared in the spectrum of poly(HxFTFA). The spectra in Figures 1(B) and 2(B) lead to the tentative conclusion that addition polymerization of the vinyl group takes place predominantly without appreciable side reactions.

According to the GPC eluogram of poly(TFTFA) obtained with $\mathrm{LiZnC}_{4} \mathrm{H}_{9}\left(\mathrm{C}_{2} \mathrm{H}_{5}\right)_{2}$ in DME, as shown in Figure 3, the molecular weight distribution is unimodal and the molecular weight of the peak based on the standardized poly(styrene) calibration is $3.5 \times 10^{4}$. It is of interest that the refractive index of a solution of poly(TFTFA) is lower than that of the solvent, THF, as has been found in the case of poly(2,2,2-trifluoro-1-trifluoromethylethyl methacrylate). ${ }^{5}$

The thermal character of poly(HxFTFA) was analyzed by TG-DSC. The polymer began to decompose at $250^{\circ} \mathrm{C}$. No peak or onset corresponding to $T_{\mathrm{g}}$ or $T_{\mathrm{m}}$ was observed below the decomposition temperature.
Acknowledgement. This work was supported in part by a grant from Nissan Science Foundation, which we gratefully acknowledged.

\section{REFERENCES}

1. T. Narita, T. Hagiwara, and H. Hamana, Makromol. Chem., Rapid Commun., 6, 5 (1985).

2. S. Iwatsuki, A. Kondo, and H. Harashima, Macromolecules, 17, 2473 (1984).

3. T. Narita, T. Hagiwara, and H. Hamana, Makromol. Chem., Rapid Commun., 6, 175 (1985).

4. T. Narita, T. Hagiwara, and H. Hamana, Nippon Kagaku Kaishi, 1945 (1985).

5. T. Narita, T. Hagiwara, H. Hamana, and M. Goto, Makromol. Chem., 187, 731 (1986).

6. T. Narita, T. Hagiwara, H. Hamana, H. Yanagisawa, and Y. Akazawa, Makromol. Chem., 187, 739 (1986).

7. T. Narita, T. Hagiwara, H. Hamana, T. Miyasaka, A. Wakayama, and T. Hotta, Makromol. Chem., 188, 273 (1987).

8. T. Narita, T. Hagiwara, H. Hamana, and T. Nara, Makromol. Chem., Rapid Commun., 6, 301 (1985).

9. T. Narita, T. Hagiwara, H. Hamana, and T. Nara, polym. J., 20, 277 (1988).

10. H. Ito, D. C. Miller, and C. G. Willson, Macromolecules, 15, 915 (1982).

11. H. Ito and R. Schwalm, Polym. Prepr., Am. Chem. Soc. Div. Polym. Chem., 27, 196 (1986).

12. Y. Kawakami and T. Tsuruta, Bull. Chem. Soc. Jpn., 44, 247 (1971). 